\title{
Food-related hazards in China: consumers' perceptions of risk and trust in information sources
}

\author{
Rongduo Liu ${ }^{a, b^{*}}$, Zuzanna Pieniak $^{a}$, Wim Verbeke ${ }^{a}$ \\ a Department of Agricultural Economics, Ghent University, Coupure links 653, Ghent 9000, Belgium \\ ${ }^{\mathrm{b}}$ Department of Finance, China Women's University, Beijing, 100101, China
}

\section{Introduction}

An increased frequency of food scares in China in recent years has increased Chinese consumers' worries about food safety and reduced their confidence in the quality of food. A better understanding of Chinese consumers' perceptions of food-related risks and their trust in information sources would help improve effective communication about food hazards to Chinese consumers in China and thereby rebuild their confidence in food safety. The objectives of this study are: first, to identify different segments of Chinese consumers, based on their personal risk perceptions, their degree of worry and their knowledge about food-related hazards; second, to investigate whether the identified segments differ in terms of their use of information channels about food-related hazards and their trust in information sources; and last, to investigate the determinants of trust in information sources.

\section{Material and methods}

Quantitative data were collected during March 2012 through a self-administrated structured questionnaire conducted in Beijing based on convenience sampling (534 participants) and Baoding city based on self-selection sampling (437 participants). A two-step clustering procedure was applied to identify distinctive consumer segmentation. A multiple linear regression analysis was conducted for each information source to investigate the determinants of trust in information sources.

\section{Results}

Participants generally reported a high level of worry about all food-related hazards. The two hazards that participants were most worried about were counterfeit food and inferior food. Participants reported a neutral degree of subjective knowledge about all food-related hazards. Television and internet were the most widely used information channels. Medical and personal sources were perceived as most trustworthy about food safety. The least trusted source of information were food producers. Trust was determined by perceived sources' knowledge, honesty and concern. Three distinctive consumer segments were achieved.

\section{Discussion}

More collaboration between government departments, medical doctors and research institutes would improve the public's confidence in the credibility of information about food safety. Since Chinese people increasingly use the internet as an information channel, more accurate, transparent and up-to-date information should be put on official websites. Although the government is perceived as a reliable source, its perceived trustworthiness could be increased if it were to show more concern about citizen's health. Supervision of food producers by public authorities would go a long way to restoring consumers' trust. The identification of three distinct segments shows that the information channels and sources need to be chosen carefully in accordance with the needs of target consumers.

\section{Reference}

1. Rosati, S., \& Saba, A. (2004). The perception of risks associated with food-related hazards and the perceived reliability of sources of information. Int. J. Food Sci. Technol., 39(5), 491-500.

2. Frewer, L. J. et al. (1996). What determines trust in information about food-related risks? Underlying psychological constructs. Risk Anal., 16(4), 473-486. 